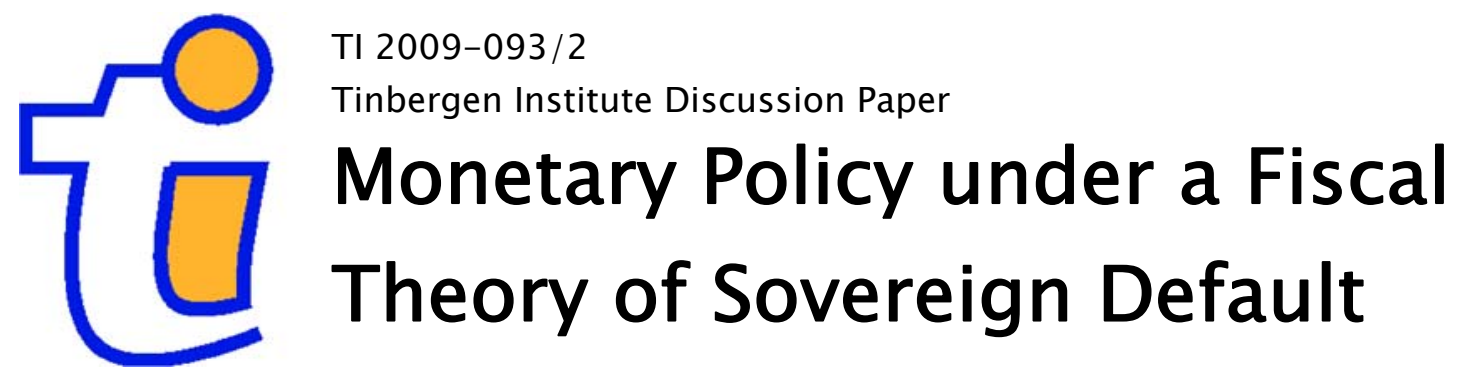

Andreas Schabert

TU Dortmund University, and University of Amsterdam, Tinbergen Institute. 


\section{Tinbergen Institute}

The Tinbergen Institute is the institute for economic research of the Erasmus Universiteit Rotterdam, Universiteit van Amsterdam, and Vrije Universiteit Amsterdam.

Tinbergen Institute Amsterdam

Roetersstraat 31

1018 WB Amsterdam

The Netherlands

Tel.: +31(0)205513500

Fax: $+31(0) 205513555$

Tinbergen Institute Rotterdam

Burg. Oudlaan 50

3062 PA Rotterdam

The Netherlands

Tel.: + $31(0) 104088900$

Fax: $+31(0) 104089031$

Most TI discussion papers can be downloaded at http://www.tinbergen.nl. 


\title{
Monetary policy under a fiscal theory of sovereign default ${ }^{1}$
}

\author{
Andreas Schabert ${ }^{2}$ \\ TU Dortmund University and University of Amsterdam
}

October 2009

\begin{abstract}
This paper examines equilibrium determination under different monetary policy regimes when the government might default on its debt. We apply a cash-inadvance model where the government does not have access to non-distortionary taxation and does not account for initial outstanding debt when it sets the income tax rate. Solvency is then not guaranteed and sovereign default can affect the return on public debt. If the central bank sets the interest rate in a conventional way, the equilibrium allocation cannot be determined. If, instead, money supply is controlled, the equilibrium allocation can uniquely be determined.
\end{abstract}

JEL classification: E31, E52, E63.

Keywords: Equilibrium determination, interest rate policy, money supply, public debt, sovereign default

\footnotetext{
${ }^{1}$ The author would like to thank Roel Beetsma, Wouter den Haan, Mark Gertler, Philipp Harms, Dirk Niepelt, Leopold von Thadden, and other seminar participants at the Federal Reserve Bank of New York, the Free University Berlin, and the University of Amsterdam for helpful comments. This work has been supported in part by the Collaborative Research Center SFB 823 of the German Research Foundation (DFG). The usual disclaimer applies.

${ }^{2}$ TU Dortmund University, Department of Economics, Vogelpothsweg 87, 44227 Dortmund, Germany, Email: andreas.schabert@udo.edu, Phone: +49 231755 3288, Fax: +49 2317553069.
} 


\section{Introduction}

How should monetary policy be conducted when fiscal policy does not guarantee full debt repayment? [9] suggests that central banks should control monetary aggregates if interest rates are associated with default risk. In this paper, we provide a formal analysis of this question by extending the "Fiscal Theory of Sovereign Risk" of [10] to a simple framework where money serves as a means of payment and government surpluses are endogenous. Fiscal policy does not guarantee full debt repayment, such that sovereign default affects the effective rate of return on government bonds. Conducting monetary policy by setting the nominal interest rate then fails to determine the equilibrium allocation, while the equilibrium allocation and the associated price system can uniquely be determined under a money growth policy. ${ }^{3}$

It is known that monetary policy can be severely constrained by fiscal policy, in particular when the government fails to guarantee government solvency (see e.g. [2] or [3]). Most prominently, the fiscal theory of the price level (FTPL) has demonstrated that monetary policy is required to accommodate fiscal policy, when the government decides on primary surpluses irrespective of outstanding debt. ${ }^{4}$ We depart from the FTPL approach and consider that investors/households account for the possibility of sovereign default due to intertemporal insolvency, consistent with the criticism raised by [7]. In contrast to the set-up in [10], we allow production to be endogenous and assume that non-distortionary taxes are not available such that tax revenues depend on the equilibrium allocation. The income tax rate is assumed to be constant and does not guarantee debt obligations to be fully serviced. Sovereign default can occur if the present value of endogenous revenues from distortionary taxation and from seigniorage are too low, while we do not consider the case where the government strategically defaults on debt.

Due to a cash-in-advance constraint monetary policy is non-neutral and might affect the equilibrium allocation and government revenues. We show that monetary policy implementation is decisive for the determination of the equilibrium allocation. Since debt

\footnotetext{
${ }^{3}$ This analysis adds a new argument to the debate on equilibrium determinacy under money growth rules (see [6] for an overview).

${ }^{4}$ See [11] and [12].
} 
obligations might not fully be served, the actual debt repayment rate and the contractual interest rate on public debt jointly affect the saving decision of households. A standard interest rate policy (regardless whether interest rates are set exogenously or contingent on macroeconomic indicators) is then ineffective in the sense that neither the equilibrium allocation nor the associated price system can be determined. In contrast, if the central bank controls the money growth rate, the equilibrium allocation and the associated price level can uniquely be determined.

The remainder of this paper is organized as follows. Section 2 presents the model. In section 3 equilibrium determination under different monetary policy regimes is examined. Section 4 concludes.

\section{The model}

This section presents a simple perfect foresight model with a cash-credit good distortion and a labor income tax. The government is assumed not to have access to lump-sum taxation. Following [10], we assume that tax revenues do not necessarily suffice to serve debt obligations, and - departing from the literature that considers strategic default ${ }^{5}-$ we assume that the government is able to commit to its promises and serves its debt obligations as far as possible, for a given monetary and tax policy.

The private sector There exists a continuum of infinitely lived and identical households of mass one. Their utility increases in consumption $c_{t}$ and decreases in working time $l_{t}$, the latter variable being bounded by $l_{t} \in(0,1)$. The objective of a representative household is given by

$$
\max \sum_{t=0}^{\infty} \beta^{t} u\left(c_{t}, l_{t}\right), \quad \text { with } \beta \in(0,1),
$$

where $\beta$ denotes the discount factor. To facilitate a global determinacy analysis we will assume that instantaneous utility satisfies $u\left(c_{t}, l_{t}\right)=\log c_{t}+\left(1-l_{t}\right)$. Households enter a period $t$ with three types of nominal assets: Money balances $M_{t-1}$, privately issued debt $D_{t-1}$, and government bonds $B_{t-1}$. In period $t$ private debt is issued at the price $1 / R_{t}^{d}$ and government debt is issued at the price $1 / R_{t}$. Labor income is taxed with a tax rate

\footnotetext{
${ }^{5}$ See for example [4] or more recently [1].
} 
$\tau_{t} \in(0,1)$. The budget constraint reads

$$
P_{t} c_{t}+\left(B_{t} / R_{t}\right)+M_{t}+\left(D_{t} / R_{t}^{d}\right) \leq\left(1-\tau_{t}\right) P_{t} w_{t} l_{t}+\left(1-\delta_{t}\right) B_{t-1}+D_{t-1}+M_{t-1}+\Gamma_{t},
$$

where $P_{t}$ denotes the goods' price level, $w_{t}$ the real wage rate, and $\Gamma_{t}$ firms' profits. Households take into account that government debt might not be fully repaid, where expectations about the repayment rate $1-\delta_{t} \geq 0$ depend on current and future government surpluses (see [10]). Households have to satisfy a no-Ponzi game condition,

$$
\lim _{t \rightarrow \infty}\left(D_{t} / R_{t}^{d}\right) \prod_{i=1}^{t}\left(1 / R_{i-1}^{d}\right) \geq 0,
$$

and cannot borrow in terms of government liabilities, $B_{t} \geq 0$ and $M_{t} \geq 0$.

In each period the asset market opens before the goods market, which relates to the timing of events in [5]. We assume that money serves as a means of payment in both markets. In period $t$ households receive cash payoffs $M_{t-1}+\left(1-\delta_{t}\right) B_{t-1}+D_{t-1}$ and spend the amount $\left(B_{t} / R_{t}\right)+\left(D_{t} / R_{t}^{d}\right)$ on interest bearing assets, such that their cash holdings equal $M_{t-1}+\left(1-\delta_{t}\right) B_{t-1}+D_{t-1}-\left(B_{t} / R_{t}\right)-\left(D_{t} / R_{t}^{d}\right)$ when they leave the asset market. Hence, they face the following cash-in-advance constraint in the goods market

$$
P_{t} c_{t} \leq M_{t-1}+\left(1-\delta_{t}\right) B_{t-1}+D_{t-1}-\left(B_{t} / R_{t}\right)-\left(D_{t} / R_{t}^{d}\right)
$$

This specification is chosen to facilitate the determinacy analysis, while leading to the same set of first order conditions as the specification of [5]. According to (3), consumption as well as assets are cash goods, whereas leisure is treated as a credit good. In equilibrium, working-time and the allocation will therefore be affected by the opportunity costs of money holdings, like under a working capital constraint for firms. The latter would require firms to pay out wages in cash before the goods market opens, which distorts firms' labor demand decision by additional costs of borrowing money, leaving consumption based asset pricing unaffected (see 5 and 6).

Maximizing life-time utility with respect to the budget constraint, the borrowing constraints, and the cash constraint, taking prices and initial asset endowments $M_{-1}>0$, 
$B_{-1}>0$, and $D_{-1}=0$ as given, leads to the following first order conditions $\forall t \geq 0$ :

$$
\begin{aligned}
& -u_{l}\left(c_{t}, l_{t}\right) R_{t}\left(1-\delta_{t+1}\right)=u_{c}\left(c_{t}, l_{t}\right)\left(1-\tau_{t}\right) w_{t}, \\
& u_{c}\left(c_{t}, l_{t}\right) / u_{c}\left(c_{t+1}, l_{t+1}\right)=\beta\left(1-\delta_{t+1}\right) R_{t} / \pi_{t+1}, \\
& u_{c}\left(c_{t}, l_{t}\right) / u_{c}\left(c_{t+1}, l_{t+1}\right)=\beta R_{t}^{d} / \pi_{t+1},
\end{aligned}
$$

$(3)$, and $\psi_{t}\left(M_{t-1}+\left(1-\delta_{t}\right) B_{t-1}+D_{t}-\left(B_{t} / R_{t}\right)-\left(D_{t} / R_{t}^{d}\right)-P_{t} c_{t}\right) \geq 0$, where $\psi_{t}$ is the multiplier on (3) satisfying

$$
\psi_{t}=\left(R_{t}^{d}-1\right) /\left[\left(1-\tau_{t}\right) w_{t}\right] \geq 0
$$

Moreover, the budget constraint (2) and the no-Ponzi game condition hold with equality, while the non-negativity constraints on money and bonds will only be relevant for $t \rightarrow \infty$. Thus, the household's optimum is further characterized by the transversality conditions

$$
\lim _{t \rightarrow \infty} x_{t} \prod_{i=1}^{t}\left(\pi_{i} / R_{i-1}^{d}\right)=0,
$$

where $x_{t} \in\left\{d_{t} / R_{t}^{d}, b_{t} / R_{t}, m_{t}\right\}$ and $b_{t}=B_{t} / P_{t}, d_{t}=D_{t} / P_{t}, m_{t}=M_{t} / P_{t}$, and $\pi_{t}=$ $P_{t} / P_{t-1}$.

We assume that perfectly competitive firms produce the final good $y_{t}$ with a linear technology $y_{t}=l_{t}$, leading to a real wage rate equal to one, $w_{t}=1$.

The public sector The public sector consists of a central bank and a government. We assume that the government does not have access to lump-sum taxation. It issues debt, raises tax revenues by taxing labor income, and purchases the amount $g_{t}$ of the final good in each period. It further receives transfers $\tau_{t}^{m}$ from the central bank. The government budget constraint is

$$
B_{t} R_{t}^{-1}+P_{t} \tau_{t} w_{t} l_{t}+P_{t} \tau_{t}^{m}=P_{t} g_{t}+\left(1-\delta_{t}\right) B_{t-1},
$$

or $B_{t} R_{t}^{-1}+P_{t} s_{t}=\left(1-\delta_{t}\right) B_{t-1}$, where $s_{t}$ denotes surpluses

$$
s_{t}=\tau_{t} w_{t} l_{t}+\tau_{t}^{m}-g_{t} .
$$


Due to distortionary taxation and seigniorage revenues surpluses are endogenous and will depend on the equilibrium allocation. Rewriting (8) in real terms, $\left(1-\delta_{0}\right) B_{-1} / P_{0}=$ $b_{0} R_{0}^{-1}+s_{0}$ and $\left(1-\delta_{t+1}\right) b_{t} / \pi_{t+1}=b_{t+1} R_{t+1}^{-1}+s_{t+1}$, and iterating forward, yields the intertemporal government budget constraint

$$
\left(1-\delta_{0}\right) B_{-1} / P_{0}=\sum_{t=0}^{\infty} s_{t} \prod_{i=1}^{t} \frac{\pi_{i}}{\left(1-\delta_{i}\right) R_{i-1}}+\lim _{t \rightarrow \infty} b_{t} R_{t}^{-1} \prod_{i=1}^{t} \frac{\pi_{i}}{\left(1-\delta_{i}\right) R_{i-1}}
$$

We assume that the fiscal authority decides on taxes without taking into account initial outstanding debt. In particular, we assume that the labor income tax rate is set equal to a constant

$$
\tau_{t}=\tau \in(0,1)
$$

which can in principle be justified by the government's aim to minimize of tax distortions. The share of government expenditures $g_{t} / y_{t}$ is assumed to be exogenously given and, for simplicity, constant: $\gamma /(1+\gamma)=g_{t} / y_{t}$ or $\gamma=g_{t} / c_{t}$, where $\gamma \geq 0$. We assume that the government is able to commit to fulfill debt repayment obligations as far as possible for any equilibrium surplus sequence. Thus, sovereign default $\delta_{t}>0$ can occur when current and future discounted revenues from income taxation and from seigniorage are too low.

The central bank either sets the money growth rate $M_{t} / M_{t-1}$ or the nominal interest rate on bonds $R_{t}$. Like in [10], it cannot set the risk-free interest rate on private debt. The central bank transfers seigniorage revenues to the fiscal authority:

$$
M_{t}-M_{t-1}=P_{t} \tau_{t}^{m}
$$

\section{Monetary policy and equilibrium determination}

In equilibrium prices adjust to clear markets for labor, goods $\left(y_{t}=c_{t}+g_{t}\right)$, and assets (i.a. $\left.D_{t}=0\right)$. Using (5) and (6) to get $R_{t}^{d}=\left(1-\delta_{t+1}\right) R_{t}$, we can combine the transversality condition on bonds ( 7 with $x_{t}=b_{t} / R_{t}$ ) with the intertemporal budget constraint (9) to give

$$
\left(1-\delta_{0}\right) B_{-1} / P_{0}=\sum_{t=0}^{\infty} s_{t} \prod_{i=1}^{t} \frac{\pi_{i}}{\left(1-\delta_{i}\right) R_{i-1}}
$$


In equilibrium, the sequences $\left\{c_{t}, l_{t}, y_{t}, w_{t}, \pi_{t+1}, \tau_{t}^{m}, m_{t} \geq 0, b_{t} \geq 0, \delta_{t} \leq 1, R_{t} \geq\right.$ $1\}_{t=0}^{\infty}$ and the initial price level $P_{0}>0$ have to satisfy (4), (5), $m_{t} \geq c_{t}+g_{t}-\tau_{t} w_{t} l_{t}$, $\lim _{t \rightarrow \infty} m_{t} \Pi_{i=1}^{t} \pi_{i} /\left[\left(1-\delta_{i}\right) R_{i-1}\right]=0, y_{t}=c_{t}+g_{t}, y_{t}=l_{t}, w_{t}=1, b_{t} R_{t}^{-1}+s_{t}=$ $\left(1-\delta_{t}\right) b_{t-1} \pi_{t}^{-1},\left(\right.$ where $\left.s_{t}=\tau_{t} w_{t} l_{t}+\tau_{t}^{m}-g_{t}\right), \tau_{t}^{m}=\frac{\mu_{t}-1}{\mu_{t}} m_{t}\left(\right.$ where $\mu_{t}=m_{t} \pi_{t} / m_{t-1}$ and $\left.\mu_{0}=m_{0} P_{0} / M_{-1}\right)$, and (11), given a fiscal policy, (10) and $\gamma=g_{t} / c_{t}$, a monetary policy and initial values $M_{-1}>0$ and $B_{-1}>0$.

The cash constraint will be binding if $\psi_{t}=\left(\left(1-\delta_{t+1}\right) R_{t}-1\right) /(1-\tau)>0 \Rightarrow$

$$
\pi_{t+1}>\beta c_{t} / c_{t+1}
$$

Further using $u_{l}\left(c_{t}, l_{t}\right)=-1, u_{c}\left(c_{t}, l_{t}\right)=1 / c_{t}$, and $\Pi_{i=1}^{t} \pi_{i} /\left[\left(1-\delta_{i}\right) R_{i-1}\right]=\beta^{t} \frac{c_{0}}{c_{t}}$, the equilibrium can be defined as follows:

Definition $1 A$ competitive equilibrium is a set of sequences $\left\{c_{t}, \pi_{t+1}, m_{t} \geq 0, y_{t} \in\right.$ $\left.(0,1), R_{t} \geq 1, \delta_{t} \leq 1, b_{t} \geq 0\right\}_{t=0}^{\infty}$ and $P_{0}>0$ satisfying

$$
\begin{aligned}
& c_{t}=\frac{1-\tau}{R_{t}\left(1-\delta_{t+1}\right)}, \\
& \frac{c_{t+1}}{c_{t}}=\beta \frac{\left(1-\delta_{t+1}\right) R_{t}}{\pi_{t+1}}, \\
& y_{t}=c_{t}(1+\gamma), \\
& m_{t}=c_{t}(1-\tau)(1+\gamma), \quad \text { if } \pi_{t+1}>\beta c_{t} / c_{t+1}, \\
& \quad \text { or } m_{t} \geq c_{t}(1-\tau)(1+\gamma), \quad \text { if } \pi_{t+1} \geq \beta c_{t} / c_{t+1}, \\
& b_{t+1} / R_{t+1}=[\gamma-\tau(1+\gamma)] c_{t+1}-\left[\left(\mu_{t+1}-1\right) / \mu_{t+1}\right] m_{t+1}+\left(1-\delta_{t+1}\right) b_{t} / \pi_{t+1}, \\
& \quad \text { and } b_{0} / R_{0}=[\gamma-\tau(1+\gamma)] c_{0}-\left[m_{0}-M_{-1} / P_{0}\right]+\left(1-\delta_{0}\right) B_{-1} / P_{0}, \\
& \left(1-\delta_{0}\right) B_{-1} / P_{0}=\sum_{t=0}^{\infty} \beta^{t} \frac{c_{0}}{c_{t}}\left([\tau(1+\gamma)-\gamma] c_{t}+\left[\left(\mu_{t}-1\right) / \mu_{t}\right] m_{t}\right),
\end{aligned}
$$

(where $\mu_{t+1}=m_{t+1} \pi_{t+1} / m_{t}$ and $\mu_{0}=m_{0} P_{0} / M_{-1}$ ) and (7) with $x_{t}=m_{t}$, for a fiscal policy, $\tau \in(0,1)$ and $\gamma \geq 0$, a monetary policy setting $R_{t}$ or $\mu_{t}$, given $M_{-1}>0$, and $B_{-1}>0$.

The equations (16) and (17) show that default rates depend on the equilibrium allocation. At the same time, the allocation depends on the expected default rate, which alters the opportunity costs of money holdings and thereby affects consumption (see 12). Notably, the interest rate $R_{t}$ affects consumption and inflation only in combination with the repayment rate $1-\delta_{t+1}$ (see 12 and 13), since they jointly govern the effective rate of return on bonds. 
Consider an equilibrium consumption sequence $\left\{c_{t}\right\}_{t=0}^{\infty}$. It is by (12) associated with a unique sequence for $R_{t}\left(1-\delta_{t+1}\right) \forall t \geq 0$, for inflation $\pi_{t} \forall t \geq 1$ (by 13), and if (15) is binding, for real balances $m_{t} \forall t \geq 0$, and thus for the money growth rate $\mu_{t} \forall t \geq 1$.

Corollary 1 For any equilibrium sequence $\left\{c_{t}>0\right\}_{t=0}^{\infty}$, (14) determines a unique equilibrium output sequence $\left\{y_{t}\right\} \forall t \geq 0$, (12) determines a unique equilibrium sequence of effective nominal rates of return $\left\{\left(1-\delta_{t+1}\right) R_{t}\right\} \forall t \geq 0$, and (13) determines a unique equilibrium inflation sequence $\left\{\pi_{t}>0\right\} \forall t \geq 1$.

Consider an equilibrium sequence $\left\{c_{t}\right\}_{t=0}^{\infty}$ and an initial price level $P_{0}$, and suppose that (15) is binding. By corollary 1 , inflation rates $\pi_{t} \forall t \geq 1$ are then determined and - given $\left\{c_{t}, \pi_{t}, m_{t}\right\}_{t=0}^{\infty}$ as well as $P_{0}$ - money growth rates $\mu_{t} \forall t \geq 0$ too. Hence, the RHS of (17) and thus $\left(1-\delta_{0}\right) B_{-1} / P_{0}$ are determined. Given $P_{0},(16)$ for period 0 then leads to a unique market value of real debt $b_{0} / R_{0}$ and, using (13) and (16) for $t \geq 1$, a unique sequence $\left\{b_{t} / R_{t}\right\}_{t=0}^{\infty}$ or $\left\{\left(1-\delta_{t+1}\right) b_{t} / \pi_{t+1}\right\}_{t=0}^{\infty}$, while real debt $b_{t}$ and the default rate $\delta_{t}$ $\forall t \geq 1$ cannot separately be determined. Thus, there are infinitely many real debt and default rate sequences $\left\{b_{t}, \delta_{t}\right\}_{t=0}^{\infty}$ consistent with a particular set of sequences $\left\{c_{t}, m_{t}\right\}_{t=0}^{\infty}$ and a particular initial price level $P_{0}$.

Corollary 2 For a particular set of equilibrium sequences $\left\{m_{t}, c_{t}\right\}_{t=0}^{\infty}$ and an associated initial equilibrium price level $P_{0}$, there exist a unique initial default rate $\delta_{0}$ and a unique sequence for the market value of real debt $\left\{b_{t} / R_{t}\right\}_{t=0}^{\infty}$, while there are infinitely many real debt sequences $\left\{b_{t}\right\} \forall t \geq 0$ and default rate sequences $\left\{\delta_{t}\right\} \forall t \geq 1$ consistent with a competitive equilibrium.

Interest rate policy Suppose that the central bank uses the nominal interest rate on government bonds $R_{t}$ as its instrument. It can either be set in an exogenous way or contingent on macroeconomic indicators, like on past, current, or future values of inflation $\pi_{t \pm i}$ (where $i=1,2$. .) or of output $y_{ \pm i}$. It can immediately be seen that the equilibrium allocation cannot be determined under this type of policy regime: The three conditions (12)-(14) then contain the four variables consumption, output, inflation and the default rate. The determination of consumption, output, and inflation thus requires the simultaneous determination of the equilibrium default rate $\delta_{t+1}$ (see corollary 1). For this, only (16) is available, which additionally contains (at least) real debt as an unknown variable, implying that there are infinitely many sets of sequences $\left\{c_{t}, y_{t}, \pi_{t}, \delta_{t+1}, b_{t}\right\}_{t=0}^{\infty}$ consistent 
with a competitive equilibrium. Thus, the equilibrium allocation and the price level are indetermined under a standard interest rate policy.

Proposition 1 If the central bank sets the nominal interest rate $R_{t}$ in an exogenous way or as a function of macroeconomic indicators (like inflation or output), the equilibrium allocation and the equilibrium price level cannot be determined.

The simple reason for indeterminacy under interest rate policy is that the contractual interest rate $R_{t}$ only affects the allocation via the effective rate of return (see 12), which is further altered by the expected default rate. Since the latter depends on endogenous surpluses and therefore on the equilibrium allocation (see 17), a monetary policy regime that controls the contractual interest rate leaves the equilibrium indetermined. The determination of the equilibrium allocation would only be possible, if the interest rate can be set contingent on the repayment rate $1-\delta_{t+1}$, such that the central bank would actually control the effective rate of return $\left(1-\delta_{t+1}\right) R_{t}$ rather than just $R_{t}$.

If however the default rate is restricted to equal zero $\delta_{t}=0$, like under the FTPL, the equilibrium can uniquely be determined under an interest rate policy (see [8] or [13]). In particular, an interest rate peg would then pin down consumption at $c_{t}=(1-\tau) / R$ (see 12) and inflation at $\pi_{t+1}=\beta R$ (see 13), while a unique initial price level can then be identified using (15) and (17) for a given $M_{-1}$.

Money growth policy Now suppose that the central bank supplies money according to a constant money growth rate

$$
\mu=M_{t} / M_{t-1} \quad \forall t \geq 0 .
$$

Suppose that the cash constraint (15) is binding, such that $\mu / \pi_{t+1}=c_{t+1} / c_{t}$. Combining (12) and (13) to $c_{t+1}=\beta \frac{1-\tau}{\pi_{t+1}}$, we can simplify pin down consumption

$$
c_{t}=\beta(1-\tau) / \mu,
$$

output $y_{t}=\beta \frac{1-\tau}{\mu}(1+\gamma)$ by (14), real balances $m_{t}=\beta \mu^{-1}(1-\tau)^{2}(1+\gamma)$ by $(15)$, and the inflation rate $\pi_{t+1}=\mu$, implying that $\mu>\beta$ is required for the cash constraint to be binding. Given that the sequence $\left\{M_{t}\right\}_{t=0}^{\infty}$ is predetermined, the initial price level $P_{0}$ is determined by $\mu M_{-1}=M_{0}=m_{0} P_{0}$. With the binding cash constraint (15) and the 
consumption solution we get

$$
P_{0}=\frac{\mu^{2} M_{-1}}{\beta(1-\tau)^{2}(1+\gamma)}
$$

Since the inflation rates $\pi_{t}=P_{t} / P_{t-1} \forall t \geq 1$ are known, the price level sequence is also pinned down as well as the effective rate of return $\left(1-\delta_{t+1}\right) R_{t}=\mu / \beta$ (see corollary 1 ).

Using the solutions for $c_{t}, m_{t}$, and $\mu_{t}=\mu,(17)$ can be simplified to $\left(1-\delta_{0}\right) B_{-1} / P_{0}=$ $\beta \frac{1-\tau}{\mu^{2}} \frac{\mu-(1-\tau)(1+\gamma)}{1-\beta}$, and with the initial price level (18), the initial default rate is given by

$$
\delta_{0}=1-\frac{M_{-1}}{B_{-1}} \frac{\mu-(1-\tau)(1+\gamma)}{(1-\beta)(1-\tau)(1+\gamma)}
$$

While the initial default rate $\delta_{0}$ is uniquely determined, the subsequent default rates and real debt are indetermined (see corollary 2) as well as the interest rate $R_{t}$. Since the default rate is restricted to satisfy $\delta_{t} \leq 1$, the existence of an equilibrium requires the money growth rate to be sufficiently large, $\mu>(1-\tau)(1+\gamma)$ (see 19), which suffices to ensure that the household's time constraint, $l_{t}=y_{t} \in(0,1) \Rightarrow \mu>\beta \frac{1-\tau}{1+\gamma}$, is satisfied.

Corollary 3 If the central bank holds the money growth rate constant with $\mu>\max \{\beta$, $(1-\tau)(1+\gamma)\}$, the equilibrium allocation $\left\{c_{t}, y_{t}\right\}_{t=0}^{\infty}$, the price level $P_{t} \forall t \geq 0$, the effective nominal rate of return $\left(1-\delta_{t+1}\right) R_{t} \forall t \geq 0$, the market value of real debt $b_{t} / R_{t} \forall t \geq 0$, and the initial default rate $\delta_{0} \leq 1$ are uniquely determined, while real debt $b_{t} \forall t \geq 0$, the interest rate $R_{t} \forall t \geq 0$, and the default rates $\delta_{t} \forall t \geq 1$ are indetermined.

In contrast to the case where the central bank controls the interest rate, the equilibrium allocation and the associated price level sequence can uniquely be determined if the central bank controls the money growth rate. For a binding cash constraint (15), nominal consumption is determined by the supply of money. At the same time, real consumption decreases with the inflation tax by $c_{t+1}=\beta \frac{1-\tau}{\pi_{t+1}}$ (see 12 and 13). Due to these opposing effects of the money growth rate, real consumption (and real balances) can uniquely be pinned down and the price level sequence can be deduced from given nominal balances. Real debt and future default rates are indetermined, like in the previous case of an interest rate policy, as well as the contractual interest rate. In contrast, the initial default rate is determined and decreases with the money growth rate (see 19) due to the positive impact 
of money growth on discounted seigniorage revenues,

$$
\beta^{t} \frac{c_{0}}{c_{t}} \tau_{t}^{m}=c_{0} \beta^{t}(1-\tau)(1+\gamma)(1-1 / \mu)
$$

If one assumes that the government will never default $\delta_{t}=0$, like under the FTPL, (19) implies that there exists only one money growth rate that is consistent with equilibrium, namely,

$$
\mu=(1-\tau)(1+\gamma)+(1-\beta)(1-\tau)(1+\gamma) B_{-1} / M_{-1}
$$

Otherwise, the intertemporal government budget constraint (9) would be inconsistent with the household's transversality condition on bonds.

According to corollary 3, the competitive equilibrium as summarized in definition 1 is again not fully determined, since fiscal variables cannot be pinned down. However, we can define a monetary equilibrium as follows:

Definition $2 A$ monetary equilibrium is a set of sequences $\left\{c_{t}, y_{t} \in(0, \bar{l}), m_{t} \geq 0, P_{t}>\right.$ $0\}_{t=0}^{\infty}$ satisfying $c_{t+1}=\beta \frac{1-\tau}{\pi_{t+1}}$, (14), (15), and $\lim _{t \rightarrow \infty} m_{t} \beta^{t} c_{0} / c_{t}$, for a fiscal policy, $\tau \in$ $(0,1)$ and $\gamma \geq 0$, and a central bank controlling money supply given $M_{-1}>0$.

A similar redefinition of the equilibrium is evidently not possible for the case where the central bank controls the interest rate. Using corollary 3, we can immediately infer that a monetary equilibrium can uniquely be determined.

Proposition 2 There exist a unique monetary equilibrium if the central bank supplies money according to

$$
\mu>\max \{\beta,(1-\tau)(1+\gamma)\}
$$

Hence, by controlling the money growth rate the central bank can ensure determinacy of a monetary equilibrium. This policy sidesteps public debt issues, and leaves real debt and the future default rate indetermined, which are irrelevant for the equilibrium allocation and the associated price level under a money supply policy.

Discussion The main results summarized in proposition 1 and 2 depend on the way fiscal policy is modelled here. If, for example, the default rate is modelled as a policy instrument, like the tax rate, the properties of the model and the conclusions can be different. For the case, where the government exogenously determines the default rate, 
the results would be similar to the FTPL case. The restriction $\delta_{t}=0$ is, for example, a special case for an exogenously determined default rate. As noted above, the equilibrium allocation and the equilibrium price level can then be determined under an interest rate policy. For higher exogenous default rates, consumption would increase and the price level would decrease (see 12 and 17). A feasible money growth policy would then be restricted by (19), and $\mu$ would decrease with the default rate to be consistent with equilibrium.

If fiscal policy is assumed to levy lump-sum taxes rather than income taxes, leaving all other assumptions unchanged, the main results of the paper would not be affected. If, however, it is further assumed that the government guarantees solvency, (11) with $\delta_{t}=0$, by adjusting lump-sum taxes, then the results differ. With such a "passive" fiscal policy $i$.) an interest rate peg is able to pin down consumption by $c_{t}=1 / R$, and inflation by $\pi_{t+1}=\beta R$, while the price level cannot be determined, and ii.) a money growth policy $\mu>\beta$ would pin down consumption $c_{t}=\beta / \mu$, inflation $\pi_{t}=\mu$, and the price level $P_{t}=M_{t} \mu /[(1+\gamma) \beta]$. Hence, an interest rate peg would be associated only with nominal indeterminacy rather than with nominal and real indeterminacy, which differs from the result summarized in proposition 1. In contrast, a money growth policy uniquely determines the equilibrium allocation and the equilibrium price level like in the case where default might occur (see corollary 3).

Finally, note that the results do not rely on default to be costless. Suppose for example that lenders bear time costs of default

$$
\Psi\left(\delta_{t}\right) \in[0,1], \quad \Psi^{\prime}\left(\delta_{t}\right)>0,
$$

which can for example be justified by time consuming debt repayment negotiations. Instantaneous utility would then be given by $u\left(c_{t}, l_{t}\right)=\log c_{t}+\left[1-l_{t}-\Psi\left(\delta_{t}\right)\right]$, while definition 1 would only change by $y_{t} \in\left(0,1-\Psi\left(\delta_{t}\right)\right)$. None of the previous results would be affected by default costs, except for the restriction on money growth rates (in corollary 3 and proposition 1), which then have to satisfy

$$
\mu>\max \{\beta,(1-\tau)(1+\gamma), \beta(1-\tau) /[(1+\gamma)(1-\Psi(1))]\}
$$




\section{Conclusion}

This paper contributes to the debate on the appropriate monetary policy instrument and applies a simple model of sovereign default. It is shown that monetary policy should control money supply rather than interest rates if sovereign default is possible. Under a standard interest rate policy the equilibrium allocation cannot be determined, since the effective rate of return on bonds is affected by sovereign default. Thus, the well-known (purely) nominal indeterminacy problem is thus aggravated in this case. In contrast, a central bank can uniquely implement an equilibrium allocation and an associated price level by controlling the money growth.

\section{References}

[1] C. Arellano, Default risk and income fluctuations in emerging economies, Amer. Econ. Rev. 98 (2008), 690-712.

[2] J. Benhabib, S. Eusepi, The design of monetary and fiscal policy: A global perspective, J. Econ. Theory 123 (2005), 40-73.

[3] J. Benhabib, S. Schmitt-Grohé, M. Uribe, Monetary policy and multiple equilibria, Amer. Econ. Rev. 91 (2001), 167-185.

[4] J. Eaton, M. Gersovitz, Debt with potential repudiation: theoretical and empirical analysis, Rev. Econ. Stud. 48 (1981), 289-309.

[5] R.E. Lucas Jr., Interest rates and currency prices in a two-country world, J. Monet. Econ. 10 (1982), 335-359.

[6] R. Michener, B. Ravikumar, Chaotic dynamics in a cash-in-advance economy, J. Econ. Dynam. Control 22 (1998), 1117-1137.

[7] D. Niepelt, The fiscal myth of the price level, Quart. J. Econ. 119 (2004), 277-299.

[8] A. Schabert, L. von Thadden, Distortionary taxation, debt, and the price level, J. Money, Credit, Banking 41 (2009), 159-188.

[9] J.B. Taylor, Using monetary policy rules in emerging market economies, in: Stabilization and Monetary Policy: The International Experience, proceedings of a conference at the Bank of Mexico, 2001, pp. 441-457. 
[10] M. Uribe, A fiscal theory of sovereign risk, J. Monet. Econ. 53 (2006), 1857-1875.

[11] C. Sims, A simple model for the study of the determination of the price level and the interaction of monetary and fiscal policy, Econ. Theory 4 (1994), 381-399.

[12] M. Woodford, Monetary policy and price level determinacy in a cash-in-advance economy, Econ. Theory 4 (1994), 345-380.

[13] M. Woodford, Public debt and the price level, mimeo, Princeton University, 1998. 